DOI: 10.18276/sip.2016.45/1-08

\title{
Małgorzata Guzowska*
}

Uniwersytet Szczeciński

\section{ZASADA ALLEEGO W EKONOMII - WPROWADZENIE}

\section{Streszczenie}

Mechanizm zachowania populacji zwany obecnie efektem (zasadą) Alleego (Allee effect) został sformułowany w roku 1931 przez biologa Wardera Clyde Alleego. Głosi on, że zarówno przegęszczenie, jak i niedogęszczenie populacji może działać na nią ograniczająco. Allee zauważył, że w małych populacjach lub w populacjach rozproszonych współczynnik reprodukcji i szanse przetrwania osobników maleją, co prowadzi do wymarcia populacji.

Celem niniejszego artykułu jest przybliżenie efektu (zasady) Alleego w odniesieniu do zjawisk ekonomicznych. W artykule podjęto próbę klasyfikacji własności matematycznych, jakie powinien posiadać model ekonomiczny, którego zachowanie dynamiczne ma cechy omawianego zjawiska. Jako przykład modelu ekonomicznego zawierającego efekt Alleego zaprezentowany został model Marksa.

Słowa kluczowe: zasada Alleego, układy dynamiczne, bifurkacje, teoria chaosu

\section{Wstęp}

Zasada Alleego (Allee effect), sformułowana w roku 1931 przez biologa Wardera Clyde Allee (Allee 1939; Allee, Emerson, Park, Park, Schmidt, 1949), głosi, że zarówno przegęszczenie, jak i niedogęszczenie populacji może działać na nią ograniczająco. Allee zauważył, że w małych populacjach lub w populacjach rozproszonych współczynnik reprodukcji i szanse przetrwania osobników maleją, co prowadzi

\footnotetext{
Adres e-mail: malgorzata.guzowska@usz.edu.pl.
} 
do wymarcia populacji. Zjawisko to ma wiele przyczyn, na przykład brak różnorodności genetycznej w populacji prowadzi do jej degradacji. Również w małych populacjach ważną rolę odgrywa duża wrażliwość na czynniki losowe prowadzące do destabilizacji populacji i w konsekwencji jej wyginięcia. Duże zagęszczenie populacji też wpływa na jej rozwój ograniczająco. Przy zbyt dużym zagęszczeniu wzrasta konkurencja wewnątrzgatunkowa, co ogranicza rozwój populacji i prowadzi do wzrostu „śmiertelności”. Z punktu widzenia socjologii zasadę Alleego obrazuje przykład wielkiego miasta: im większa jest liczba jego mieszkańców, tym większy jest poziom stresu (skutkujący zakłóceniami komunikacji społecznej, rosnącą liczbą aktów agresji i nerwic). Stephenes, Sutherland i Freckleton (1999) definiują zasadę Alleego jako pozytywny stosunek (relację) pomiędzy dostosowaniem (fitness) często wyrażanym jako liczba potomstwa a zagęszczeniem przedstawicieli tego samego gatunku. W klasycznych modelach dynamiki populacji mamy do czynienia z negatywną zależnością, dostosowanie zimniejsza się wraz ze wzrostem zagęszczenia. Zjawisko Alleego przedstawia pozytywną zależność: dostosowanie maleje wraz z malejącym zagęszczeniem.

W ostatnim dziesięcioleciu do teorii tej odnosi się wielu naukowców, głównie w dziedzinie biologii i socjologii, ale także w naukach matematycznych (Courchamp, Berec, Gascoinge, 2008; Cushing, 1988; Foryś, Poleszczuk, 2011; Song, Wang, 2007; Statter, 2003). Nasuwa się więc pytanie, czy efekt ten występuje również w zjawiskach ekonomicznych.

W biologii populacja biologiczna definiowana jest jako zespół organizmów jednego gatunku żyjących równocześnie w określonym środowisku i wzajemnie na siebie wpływających, zdolnych do wydawania płodnego potomstwa. Przez modele populacji w ekonomii rozumieć będziemy nie tylko modele demograficzne, lecz także modele matematyczne pokazujące dynamikę populacji statystycznej definiowanej jako zbiór dowolnych elementów (osób, przedmiotów, faktów) podobnych pod względem określonych cech (ale nie identycznych).

\section{Efekt Alleego - ujęcie matematyczne}

Dla lepszego zrozumienia efektu Alleego warto się odnieść do własności matematycznych, jakie powinien posiadać model, którego zachowanie dynamiczne ma cechy omawianego zjawiska. 
Niech $x_{n}$ oznacza średnią liczebność populacji $x$ w jednostce czasu $t$. Następnie definiujemy dostosowanie dla $x$ jako przyrost populacji per capita zdefiniowany funkcją $f\left(x_{t}\right)=x_{t+1} / x_{t}$. Wtedy model pojedynczej populacji definiujemy jako:

$$
x_{t+1}=x_{t} \cdot f\left(x_{t}\right)=g\left(x_{t}\right) .
$$

Jeśli model (1) jest modelem z efektem Alleego, wtedy ma on trzy punkty równowagi $0, C$, oraz $K$, gdzie $C$ jest to dolny poziom krytyczny, często nazywany w literaturze punktem Alleego, innymi słowy, najmniejsza populacja żywotna (minimum viable population - MVP), natomiast $K$ to wielkość określająca pojemność środowiska (carrying capasity).

Rysunek 1. Zjawisko Alleego dla modelu pojedynczej populacji

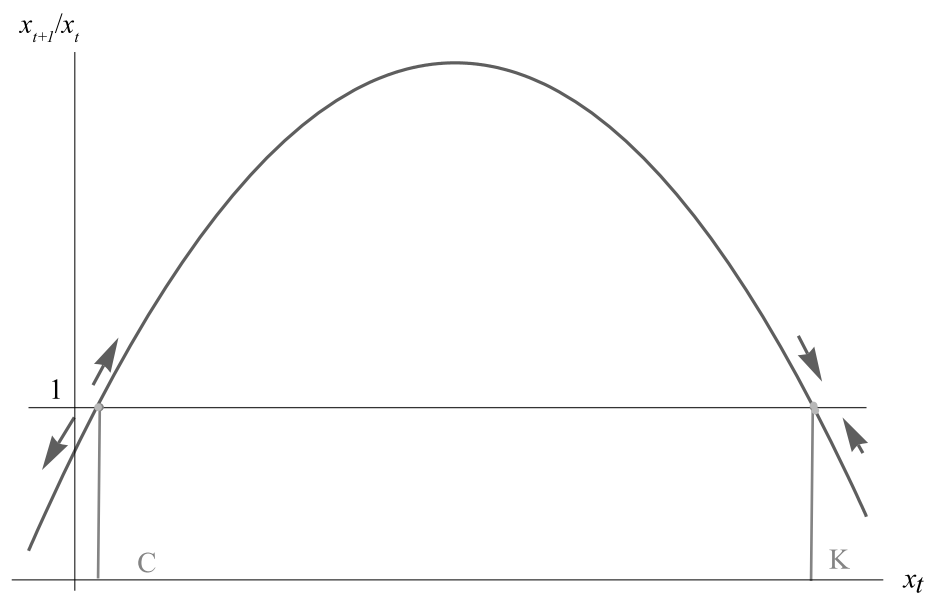

Źródło: opracowanie własne.

Gdy średnia liczebność populacji jest mniejsza od $C$, to populacja ginie (rys. 1). W przypadku, gdy średnia liczebność populacji przekroczy wielkość $C$, następuje jej wzrost i zbieżność do wielkości $K$. Po przekroczeniu pojemności środowiska następuje wzrost „śmiertelności” populacji.

Reasumując, należy podkreślić, że model obrazuje zjawisko Alleego, gdy funkcja $f$ spełnia następujące warunki:

(i) $f(0)<1$

(ii) $f^{\prime}(x)>0$ dla $x \in(0, \delta), \delta \rightarrow 0$

(iii) $f(K)=1, \quad f^{\prime}(K)<0$ 
W każdym modelu spełniającym powyższe własności można zaobserwować efekt Alleego.

\section{Model ekonomiczny z efektem Alleego}

W pracach Luis, Elaydi i Oliveira (2009) oraz Statter (2003) autorzy analizują model oparty na stopie zwrotu, wychodząc od definicji stopy zwrotu $r$ definiowanej przez Marksa jako:

$$
r=\frac{s}{v+c}
$$

gdzie: $s$ - nadwyżka, a $v+c$ to suma odpowiednio kapitału stałego $c$ i zmiennego $v$.

Nadwyżkę $s$ możemy także zdefiniować jako:

$$
s=y-(v+c)
$$

gdzie $y$ to produkcja całkowita.

Stopień eksploatacji kapitału $e$ definiujemy jako stosunek nadwyżki $s$ do kapitału zmiennego $v$ :

$$
e=\frac{s}{v}
$$

Z relacji (3) otrzymujemy równanie pokazujące relację pomiędzy stopą zwrotu $r$, stopniem eksploatacji kapitału $e$ oraz organicznym składem kapitału $k$ :

$$
r=\frac{e}{1+k}
$$

Niech $r_{n}$ będzie stopą zwrotu w czasie $n$.

Zakładamy, że stopień eksploatacji oraz organiczny skład kapitału w czasie $n+1$ zależne są od stopy zwrotu

$$
e_{n+1}=E\left(r_{n}\right), \quad k_{n+1}=K\left(r_{n}\right)
$$

Zależność stopy zwrotu w czasie $n+1$ od stopy zwrotu w czasie $n$ wyrażona jest następująco:

$$
r_{n+1}=\frac{E\left(r_{n}\right)}{1+K\left(r_{n}\right)}
$$

gdzie funkcje $E$ i $K$ zdefiniowane są następująco:

$$
E\left(r_{n}\right)=\frac{a r_{n}}{1+r_{n}^{2}}
$$




$$
K\left(r_{n}\right)=\frac{\exp \left(r_{n}-b\right)}{\left(r_{n}+d\right)^{2}}
$$

$a>0, b>0, d>0-$ stałe.

Przy czym $a>0$ mierzy względny wzrost tempa eksploatacji, gdy zyski są niskie. Wartość $K(0)=1 / d^{2} e^{b}$ określa wartość początkową, dla której organiczny kapitał w funkcji zysku rośnie nieograniczenie, co nie jest realne, ale służy do lepszego zrozumienia działania modelu. $K^{\prime}(0)=d-2 / d^{3} e^{b}$ mierzy wzrost organicznego kapitału, gdy dochody są niskie.

Wykorzystując równania (9) i (10) w równaniu (8), stopę zwrotu definiujemy ostatecznie jako:

$$
r_{n+1}=\frac{a r_{n}\left(r_{n}+d\right)^{2}}{\left(1+r_{n}^{2}\right)\left[\left(r_{n}+d\right)^{2}+e^{r_{n}-b}\right]}
$$

Przeprowadzając analizę własności dynamicznych modelu (5), (6), można pokazać, że posiada on dwa dodatnie punkty równowagi, jeżeli $a>a_{c}$, jeden punkt równowagi, gdy $a=a_{c}$, oraz nie posiada dodatnich punktów równowagi, gdy $a<a_{c}$, gdzie $a_{c}$ jest wielkością rzeczywistą zależną od parametrów $a$ i $b$.

Aby to wykazać, rozpatrujemy równanie :

$$
\frac{a(r+d)^{2}}{\left(1+r^{2}\right)\left[(r+d)^{2}+e^{r-b}\right]}=1
$$

które po zlogarytmowaniu przyjmuje postać:

$$
\ln \left(1+r^{2}\right)+\ln \left[(r+d)^{2}+e^{r-b}\right]-2 \ln (r+d)=\ln a
$$

Zdefiniujmy teraz funkcję $g$ :

$$
g(r)=\ln \left(1+r^{2}\right)+\ln \left[(r+d)^{2}+e^{r-b}\right]-2 \ln (r+d)
$$

Mamy wtedy

$$
g^{\prime}(r)=\frac{2 r}{1+r^{2}}+\frac{2(r+d)+e^{r-b}}{(r+d)^{2}+e^{r-b}}-\frac{2}{r+d}
$$


Rysunek 2. Liczba dodatnich rozwiązań (brak, jedno, dwa) dla równia stopy zwrotu (11) w zależności od parametru $a . a_{c}=1,64271$

przy ustalonych wartościach parametrów $b=3, d=0,001$

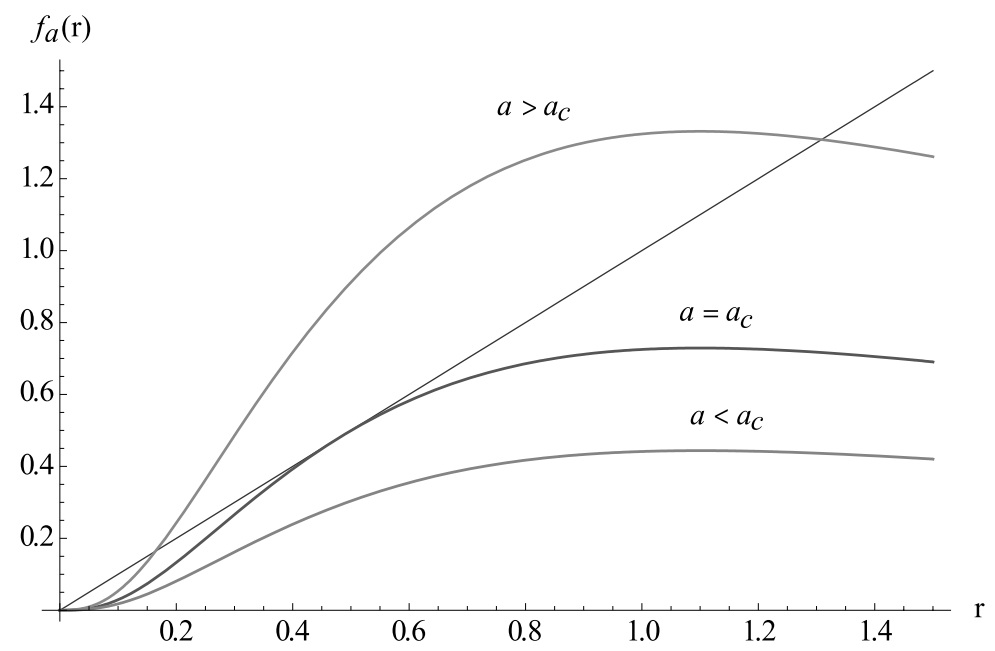

Źródło: obliczenia i opracowanie własne na podstawie Luis, Elaydi, Oliveira (2009).

Dla równania $g^{\prime}(r)=0$ otrzymujemy dodatni punkt równowagi $r_{c}$. Jednocześnie łatwo wykazać, że $g(r)>0$ dla wszystkich $r \geq 0$.

Jeśli $g\left(r_{c}\right)=\ln a_{c}$, to model (11) posiada pojedyncze dodatnie rozwiązanie $r=r_{c}$.

Jeśli $g\left(r_{d, b}\right)<\ln a_{c}$, wtedy model (11) ma dwa rozwiązania dodatnie $r_{1} i r_{2}$ $\left(r_{1}<r_{2}, r_{1}<r_{c}<r_{2}\right.$ oraz $\left.g^{\prime}\left(r_{1}\right)<0=g^{\prime}\left(r_{c}\right)<g^{\prime}\left(r_{2}\right)\right)$, oraz gdy $g\left(r_{d, b}\right)>\ln a_{c}$, wtedy brak jest dodatnich rozwiązań (11), co potwierdza wcześniejsze wnioski.

Korzystając z własności pierwszej i drugiej pochodnej funkcji, możemy także przeprowadzić analizę stabilności poszczególnych rozwiązań.

Załóżmy, że model (11) ma tylko jedno dodatnie rozwiązanie $r=r_{c}$, wtedy $f^{\prime}(r)=1-r g^{\prime}(r)$, czyli $f^{\prime}\left(r_{c}\right)=1$. Jeśli $f^{\prime \prime}\left(r_{c}\right)<0$, wynika z tego, że $r_{c}$ jest niestabilnym punktem równowagi: bardziej precyzyjnie półstabilnym z prawej strony, gdy $r_{0} \in\left(r_{c}, r_{3}\right)$, oraz niestabilnym z lewej strony, gdy $r_{0} \in\left(0, r_{3}\right)$, oraz niestabilnym, gdy $r_{0} \in\left(0, r_{c}\right) \cup\left(r_{3}, \infty\right)$ (rys. 3). 
Rysunek 3. Stabilność punktu równowagi. W pierwszym przypadku $r=r_{c}$ jest półstabilnym punktem równowagi z prawej strony, gdy $r_{0} \in\left(r_{c}, r_{3}\right)$, i niestabilnym z lewej, gdy $r_{0} \in\left(0, r_{3}\right)$. W drugim przypadku jest punktem niestabilnym, gdy $r_{0} \in\left(0, r_{c}\right) \cup\left(r_{3}, \infty\right)$
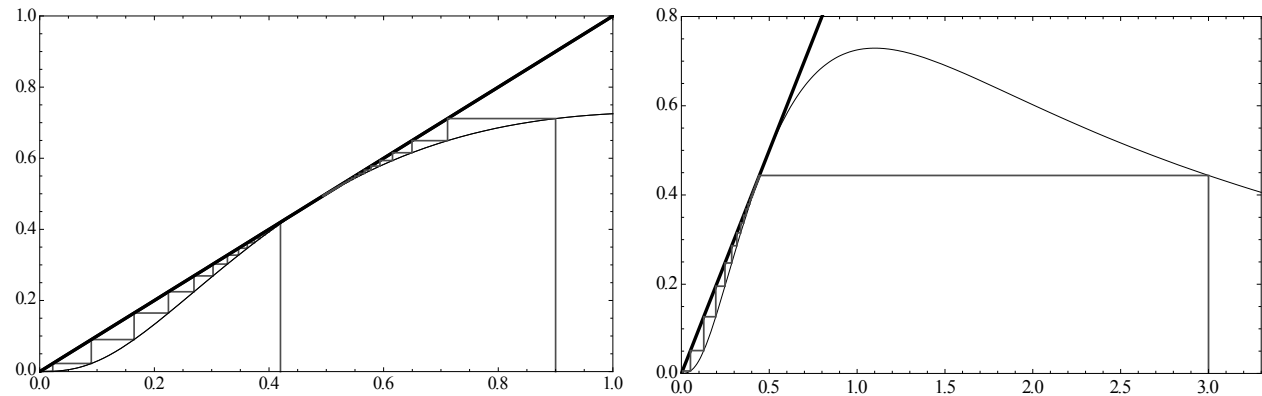

Źródło: obliczenia i opracowanie własne na podstawie Luis, Elaydi, Oliveira (2009).

Gdy równanie (9) ma dwa dodatnie punkty równowagi $r_{1} i r_{2}$, takie, że $r_{1}<r_{2}$, wtedy z własności $r_{1} g^{\prime}\left(r_{1}\right)<0$ wynika, że $r_{1}$ jest punktem niestabilnym. W przypadku $r_{2}$, ponieważ $g^{\prime}\left(r_{2}\right)>0$, stąd $r_{2} g^{\prime}\left(r_{2}\right)>0$, mamy dwa scenariusze: jeśli $0<r_{2} g^{\prime}\left(r_{2}\right)<2$, wtedy $r_{2}$ jest punktem lokalnie asymptotycznie stabilnym, natomiast w przypadku gdy $r_{2} g^{\prime}\left(r_{2}\right)>2$, wtedy $r_{2}$ jest punktem niestabilnym (rys. 4).

Rysunek 4. Stabilność dwóch dodatnich punktów równowagi. W pierwszym przypadku $r_{1}$ jest niestabilnym punktem, a $r_{2}$ punktem lokalnie asymptotycznie stabilnym. W drugim przypadku $r_{2}$ jest punktem niestabilnym
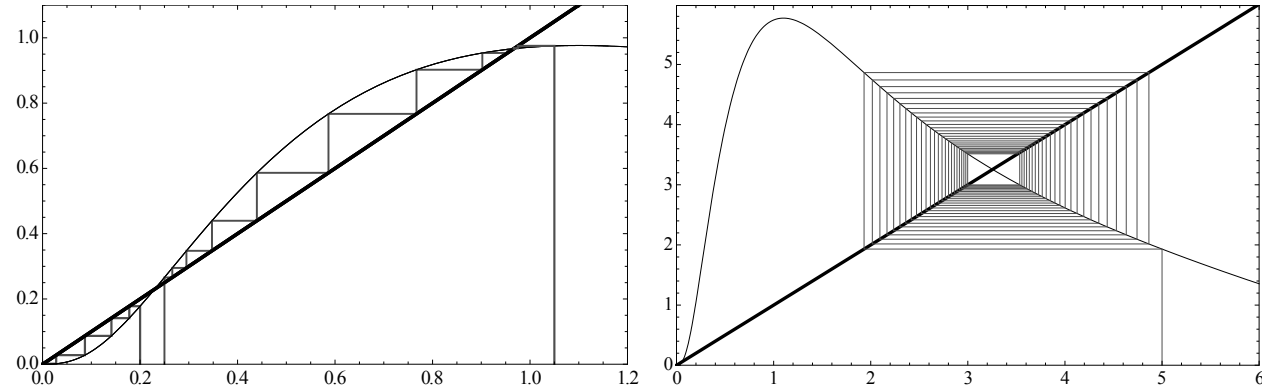

Źródło: obliczenia i opracowanie własne na podstawie Luis, Elaydi, Oliveira (2009).

Przy przyjętych do symulacji w modelu (11) wartościach parametrów można zaobserwować efekt Alleego w przypadku, gdy mamy rozwiązanie trywialne 0 oraz dwa dodatnie rozwiązania $r_{1}$ i $r_{2}$, gdy $a \in\left(a_{c}, r_{s}\right)$, gdzie dla przyjętych wartości $b$ i $d$ $a_{c} \approx 1,64271$ oraz $r_{s} \approx 3,3976$. 


\section{Podsumowanie}

Przeprowadzona analiza obrazuje występowanie efektu Alleego w modelu ekonomicznym. Nasuwa się jednak pytanie, czy taki efekt możemy zaobserwować tylko w modelach ekonomii Marksa, czy także w modelach i zjawiskach współczesnej ekonomii. Niniejszy artykuł jest wprowadzeniem do tej tematyki na gruncie nauk ekonomicznych.

\section{Literatura}

Allee, W.C. (1939). The Social Life of Animals. London: William Heinemann.

Allee, W.C., Emerson, A.E., Park, O., Park, T., Schmidt, K.P. (1949). Principles of Animal Ecology. Philadelphia: Saunders.

Courchamp, F., Berec, L., Gascoigne, J. (2008). Allee Effects. Oxford: Oxford University Press.

Cushing, J.M. (1988). The Allee Effect in Age-structured Population Dynamics. W: T. Hallam, L. Gross, S. Levin (red.), Mathematical Ecology (s. 479-505). Springer, Verlag.

Elaydi, S. (1996). An Introduction to Difference Equations. New York: Springer.

Elaydi, S. (2008). Discrete Chaos: With Applications in Science and Engineering. Boca Raton, FL: Chapman and Hall/CRC.

Foryś, U., Poleszczuk, J. (2011). Modelowanie matematyczne $w$ biologii i medycynie. Warszawa: Wyd. UW.

Li, J., Song, B., Wang, X. (2007). An Extended Discrete Ricker Population Model with Allee Effects. Journal Difference Eqations and Appications, 13, 309-321.

Luis, R., Elaydi, S., Oliveira, H. (2009). An Economic Model with Allee Effect. Journal Difference Eqations and Appications, 15, 877-894.

Statter, G. (2003). Tendencia decrecente (ou Queda Tendencial) da taxa de lucro. Preprint, ISCTE.

Stephens, P.A., Sutherland, W.J., Freckleton, R.P. (1999). What is the Allee Effect? Oikos, 87, 185-190. 


\title{
ALLE EFFECT IN ECONOMICS - INTRODUCTION
}

\begin{abstract}
The mechanism of the behavior of the population now is called the Allee effect was formulated in 1931 by the biologist Warder Clyde Allee. It says that both congestion in and small size of population can act on it limiting. Allee noted that in small populations or populations dispersed reproduction rate and survival of individuals decrease, which leads to the extinction of the population.

The purpose of this article is to introduce the Allee effect of (the rules). The article attempts to classification of property that should have mathematical economic model whose dynamic behavior has the features of this phenomenon. As an example of the economic model contains Allee effect was presented the Marx model.
\end{abstract}

Translated by Małgorzata Guzowska

Keywords: Allee effect, dynamical systems, bifurcations, chaos theory

JEL Codes: C02, C62, J00 
